\title{
Efek Metode Non Farmakologik terhadap Intensitas Nyeri Ibu Bersalin Kala I
}

\author{
Marwati Biswan $^{1}$, Henny Novita ${ }^{2}$, Masita $^{3}$ \\ ${ }_{1,2,3}$ Politeknik Kesehatan Kemenkes Jakarta I \\ Email: marwatibiswan@yahoo.com
}

\begin{abstract}
Effect of Non-Pharmacological Method on Intensity of Maternal Pain Phase I. Pain is one of the processes during the labor, the pain during the labor is able to increase the blood pressure, the fetal heart rate also increased and the focus of mothers during the childbirth is disturbed. According to data research shown that $60 \%$ primipara describes the pain caused by huge contraction, $30 \%$ about medium. In multipara, $45 \%$ feel a huge pain, $30 \%$ is medium and the lower about $25 \%$. The purpose of this research is to understand the effectivity of the proper way to the non-pharmacological pain management for the phase 1. This research used a quasiexperimental design with the pre-post test without control group design methods. The population used in this research is maternal with phase 1 on an active postpartum. The gaining of a sample using a quota sampling technic consists of 60 maternal who were divided into two groups of 30 respondents per each. The results obtained in this research given the average degree of pain after the relaxation techniques and massage. (The group I) is 5, 47 with the result of $\mathrm{p}=0.001$. The average degree of pain result after having a warm and cold compress for (the group II) is 6,60 \pm 1,003 with the result of $p=0.000$. The conclusions of the research are there are effects in an adduction of deep breathing relaxation technique such of: the back massage, cold and warm compresses toward the decreasing of pain for phase 1 active labor. The deep breath relaxation method and back massage are more effective than cold and warm compresses in relieving pain intensity for the maternal.
\end{abstract}

Keywords: Non-pharmacological pain management, Childbirth pain

\begin{abstract}
Abstrak: Efek Metode Non Farmakologik terhadap Intensitas Nyeri Ibu Bersalin Kala I. Nyeri merupakan bagian dari proses persalinan, rasa nyeri saat persalinan bisa menyebabkan tekanan darah meningkat, denyut jantung janin meningkat, dan konsentrasi ibu selama persalinan menjadi terganggu. Berdasarkan data penelitian yang ada menunjukkan bahwa $60 \%$ primipara melukiskan nyeri akibat kontraksi sangat hebat, $30 \%$ nyeri sedang. Pada multipara $45 \%$ merasakan nyeri hebat, $30 \%$ nyeri sedang dan $25 \%$ nyeri ringan. Tujuan dari penelitian ini untuk mengetahui efektifitas manajemen nyeri non farmakologik yang paling tepat terhadap pengurangan nyeri pada ibu bersalin kala I. penelitian ini menggunakan desain kuasi eksperimen dengan menggunakan metode pre-post test without control group design Populasi dalam penelitian ini adalah ibu bersalin kala I fase aktif postpartum dalam pengambilan sampelnya menggunakan teknik quota Sampling dengan sampel sebanyak 60 ibu bersalin yang dibagi menjadi 2 kelompok masingmasing 30 responden. Hasil pada penelitian ini diperoleh rerata derajat nyeri sesudah diberikan teknik relaksasi dan pijat (Kelompok I) adalah 5,47 $\pm 1,525$ dengan nilai $p=0.001$. Nilai rerata derajat nyeri sesudah diberikan kompres hangat dan kompres dingin (kelompok II) adalah 6,60 \pm 1,003 dengan nilai $p=0,000$. Ada pengaruh pemberian teknik relaksasi nafas dalam, pijat punggung, kompres hangat dan kompres dingin terhadap penurunan derajat nyeri kala I fase aktif persalinan. Metode relaksasi nafas dalam dan pijat pada punggung lebih efektif dibandingkan kompres hangat dan kompres dingin dalam menurunkan intensitas nyeri pada ibu bersalin.
\end{abstract}

Kata kunci: Nyeri, persalinan, nonfarmakologik,

Persalinan dan kelahiran adalah peristiwa fisiologis yang normal. Nyeri secara fisiologis akan dirasakan oleh ibu pada saat persalinan. Rasa nyeri saat persalinan bisa meningkatkan tekanan darah, denyut jantung janin meningkat, dan konsentrasi ibu selama persalinan menjadi terganggu. Semua itu akan berefek buruk terhadap kelancaran persalinan (Simpkin, Whalley \& Keppler 2008).

Secara umum terdapat dua faktor yang mempengaruhi intensitas nyeri yaitu faktor fisik dan psikologis. Faktor fisik antara lain: umur, paritas, besar janin, intensitas dan lama persalinan, pembukaan servik, posisi janin, 
karakteristik panggul, kelelahan, dan tindakan yang dilakukan oleh tenaga kesehatan. Sedangkan faktor psikologis meliputi: sosiobudaya setempat, tingkat kecemasan dan ketakutan, tingkat pengetahuan dan pendidikan, pengalaman nyeri sebelumnya, persiapan persalinan, dan sistem pendukung (JNPK-KR, 2008).

Nyeri pada persalinan umumnya terasa hebat, hanya $2-4 \%$ ibu saja yang mengalami nyeri ringan selama persalinan. Nyeri pada saat persalinan menempati skor 30-40 dari 50 skor yang ditetapkan oleh Wall dan Mellzack (2013). Skor tersebut lebih tinggi dibandingkan syndrome nyeri klinik seperti nyeri punggung yang kronis, nyeri akibat kanker, nyeri tungkai dan lainnya.

Nyeri yang terjadi pada proses persalinan membuat ibu hamil cenderung lebih memilih untuk menghindari proses persalinan spontan dengan melakukan seksio sesarea atau seksio sesarean on request sebagai upaya untuk tidak merasakan sensasi nyeri yang diakibatkan oleh proses persalinan spontan tersebut. Meningkatnya angka seksio sesarea di seluruh penjuru dunia sebagian besar disebabkan oleh karena adanya permintaan ibu hamil dengan alasan takut akan nyeri persalinan ini. Namun disisi lain, prosedur operasi seksio sesarea sendiri merupakan suatu prosedur intervensi obstetri yang memiliki risiko cukup besar. Penurunan keberhasilan persalinan normal terjadi oleh karena ketakutan ibu hamil akan nyeri persalinan tersebut atau ketidakmampuan ibu hamil untuk menahan dan menerima nyeri persalinan saat persalinan yang dilaluinya (Mander, 2003).

Penanganan dan pengawasan nyeri persalinan terutama pada kala I sangat penting, karena sebagai titik penentu apakah ibu bersalin dapat menjalani persalinan dengan normal atau diakhiri dengan suatu tindakan dikarenakan adanya penyulit yang diakibatkan oleh nyeri yang sangat hebat. Nyeri pada persalinan dapat dikurangi dengan menggunakan metode farmakologi dan nonfarmakologi. Jika memungkinkan pilihan metode non farmakologi untuk penatalaksanaan nyeri harus dipertimbangkan sebelum menggunakan obat analgesik. Beberapa pengelolaan nyeri secara farmakologis sebagian besar merupakan tindakan medis dan mempunyai efek samping baik bagi ibu maupun janin.

Teknik relaksasi nafas dalam merupakan teknik pereda nyeri yang banyak memberikan masukan terbesar karena relaksasi bernafas selama proses persalinan dapat mempertahankan komponen sistem saraf simpatis dalam keadaan homeostatis sehingga tidak terjadi peningkatan suplai darah, mengurangi kecemasan dan ketakutan agar ibu dapat beradaptasi dengan nyeri selama proses persalinan (Prasetyo, 2010).

Masase pada punggung merangsang titik tertentu di sepanjang meridian medulla spinalis yang ditransmisikan melalui serabut besar ke formatio retikularis, thalamus dan sistem tubuh akan melepaskan endorpin. Endorpin merupakan neurotransmitter yang menghambat pengiriman rangsang nyeri dari system saraf tulang belakang sehingga dapat memblok pesan nyeri ke pusat yang lebih tinggi dan dapat menurunkan sensasi nyeri (Cunningham, 2013).

Terapi kompres panas dan dingin merupakan salah satu metode non farmakologik untuk mengurangi nyeri. Stimulasi kulit dengan teknik kompres hangat dilakukan untuk merangsang serat syaraf yang menutup gerbang sehingga transmisi impuls nyeri ke medula spinalis dan otak dapat dihambat. Untuk stimulasi dengan kompres dingin mempunyai efek analgesik dengan memperlambat kecepatan hantaran syaraf sehingga impuls nyeri yang mencapai otak lebih sedikit (Potter \& Perry, 2005).

Pada penelitian ini menggunakan teknik kombinasi yaitu gabungan antara teknik relaksasi dan pijat pada punggung kemudian gabungan dari kompres hangat dan dingin. Dengan gabungan metode ini Bidan dapat memberikan inovasi dalam menggunakan metode-metode penatalaksanaan nyeri secara non farmakologis yang tepat agar ibu dapat melewati persalinan dengan aman. Penelitian ini bermanfaat bagi ibu bersalin sebagai informasi pilihan teknik relaksasi yang paling tepat digunakan pada kala I persalinan, sedangkan bagi tenaga kesehatan sebagai bahan masukan tentang teknik relaksasi yang paling tepat dalam melakukan penanganan nyeri pada ibu bersalin kala I. Tujuan dari penelitian ini adalah untuk mengetahui efektifitas manajemen nyeri non farmakologik yang paling tepat terhadap pengurangan nyeri pada ibu bersalin kala I.

\section{METODE}

Penelitian ini menggunakan desain kuasi eksperimen dengan menggunakan metode prepost test without control group design Populasi dalam penelitian ini adalah ibu bersalin kala I fase aktif di Puskesmas wilayah Tangerang Selatan tahun 2016. Pengambilan sampelnya menggunakan teknik quota Sampling dengan sampel sebanyak 60 ibu bersalin yang dibagi 
menjadi 2 kelompok masing-masing 30 responden.

HASIL

Intensitas Nyeri dan Karakteristik Responden

Hasil penelitian tentang variabel nyeri dan umur disajikan dengan nilai rata-rata, sedangkan untuk karakteristik responden disajikan dengan menggunakan distribusi frekuensi dan persentase. Untuk secara jelas akan disajikan dalam tabel berikut.

\begin{tabular}{|lcccc}
\hline Tabel 1. Distribusi & \multicolumn{2}{c}{ Derajat } & Nyeri & Sebelum \\
dan sesudah Intervensi & inda \\
kelompok I dan II & & \\
\hline Variabel & Mean & SD & $\begin{array}{c}\text { Median } \\
\text { (Min- } \\
\end{array}$ \\
& & & Mak) \\
\hline
\end{tabular}

\begin{tabular}{lccc}
$\begin{array}{l}\text { Nyeri sebelum } \\
\text { kelompok I }\end{array}$ & 6,77 & 1,104 & $7(4-8)$ \\
$\begin{array}{l}\text { Nyeri sesudah } \\
\text { kelompok I }\end{array}$ & 5,47 & 1,525 & $6(2-8)$ \\
$\begin{array}{l}\text { Nyeri sebelum } \\
\text { kelompok II }\end{array}$ & 6,97 & 0,809 & $7(6-8)$ \\
$\begin{array}{l}\text { Nyeri sesudah } \\
\text { kelompok II }\end{array}$ & 6,60 & 1,003 & $6(4-8)$ \\
\hline
\end{tabular}

Berdasarkan hasil penelitian diperoleh rerata derajat nyeri sebelum diberikan intervensi paling tinggi pada kelompok II yaitu 6,97 , hal ini menunjukkan rata-rata ibu bersalin mengalami nyeri sedang. Setelah diberikan intervensi penurunan rerata intensitas nyeri terlihat pada kelompok I yaitu 5,47 (nyeri sedang).

Tabel 2. Distribusi Frekuensi Karakteristik Subjek Penelitian

\begin{tabular}{lcc}
\hline Variabel & n & \% \\
\hline Umur & & \\
$\quad$ Resiko & 10 & 16,6 \\
$\quad$ Tidak beresiko & 50 & 83,3 \\
Paritas & & \\
$\quad$ Primi & 19 & 31,6 \\
$\quad$ Multi & 41 & 68,3 \\
Pendamping Persalinan & & \\
$\quad$ Anggota Kel.Lain & 11 & 18,3 \\
$\quad$ Suami & 49 & 81,6 \\
\hline
\end{tabular}

Berdasarkan tabel 2 karakteristik subjek penelitian diketahui sebagian besar responden berada pada umur tidak beresiko $(83,3 \%)$ dan dengan paritas multigravida yaitu $68,3 \%$. Pada variabel pendamping persalinan sebagian besar responden ditemani oleh suami yaitu $81,6 \%$.

\section{Pengaruh Intervensi Terhadap Intensitas Nyeri}

Tabel 3. Perbedaan Derajat Nyeri Sebelum dan Setelah Intervensi Pada Kelompok I dan II

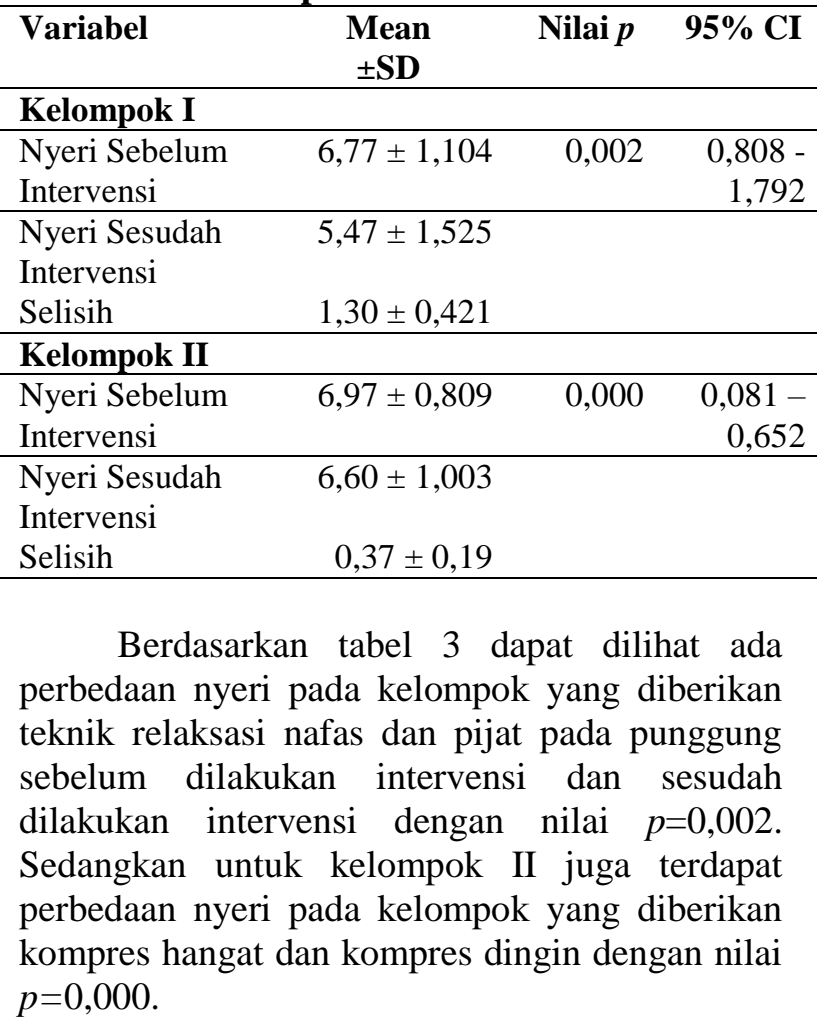

\begin{tabular}{|lcccc} 
Tabel 4. & $\begin{array}{c}\text { Perbedaan } \\
\text { Kelompok } \\
\text { Intervensi }\end{array}$ & $\begin{array}{c}\text { Derajat } \\
\text { dan }\end{array}$ & $\begin{array}{c}\text { Nyeri } \\
\text { II }\end{array}$ & $\begin{array}{c}\text { Antara } \\
\text { Setelah }\end{array}$ \\
\hline Variabel & $\begin{array}{c}\text { Mean } \\
\pm \text { SD }\end{array}$ & $\begin{array}{c}\text { Nilai } \\
\text { p }\end{array}$ & $\mathbf{9 5 \%}$ \\
Nyeri Kelompok I & $5,47 \pm 1,525$ & 0,001 & $0,838-$ \\
Nyeri kelompok II & $6,60 \pm 1,003$ & & 0,191 \\
\hline
\end{tabular}

Berdasarkan tabel di atas menunjukkan adanya perbedaan nyeri antara kelompok I dan kelompok II dengan nilai $p=0,001$.

\section{PEMBAHASAN}

\section{Karakteristik Responden}

Pada penelitian ini karakteristik responden yang diteliti meliputi umur, paritas dan pendamping persalinan. Berdasarkan faktor umur, distribusi ibu pada kelompok umur tidak beresiko lebih banyak mengalami nyeri ringan $(60 \%)$. Hasil ini sesuai dengan penelitian Adam dan Umboh (2012) bahwa ibu yang lebih muda memiliki sensori nyeri yang lebih intens dibandingkan umur ibu yang lebih tua. Umur muda cenderung dikaitkan dengan konsisi 
psikologis yang masih labil yang memicu terjadinya kecemasan sehingga nyeri yang dirasakan semakin kuat. Umur juga dipakai sebagai salah satu faktor dalam menentukan toleransi terhadap nyeri.

Pada variabel paritas, nyeri ringan lebih banyak dialami oleh ibu dengan paritas multipara $(56,1 \%)$. Hasil ini sesuai dengan pendapat Hutahaean (2009) bahwa ibu yang primipara intensitas kontraksi uterus lebih kuat dibandingkan pada ibu multipara, selain itu ibu multipara memiliki pengalaman persalinan sebelumnya sehingga akan lebih mudah beradaptasi dengan nyeri dibandingkan dengan ibu yang belum pernah memiliki pegalaman.

Pada variabel pendamping persalinan distribusi yang paling banyak pada kelompok yang didampingi oleh suami dan mengalami nyeri ringan $(63,3 \%)$. Berdasarkan Yuliastanti (2013), salah satu teknik manajemen nyeri non farmakologis yang dapat mengurangi nyeri ibu saat persalinan adalah pendampingan dari suami atau keluarga, karena efek perasaan termasuk kecemasan pada setiap ibu bersalin berkaitan dengan persepsi orang yang mendukung. Kehadiran seorang pendamping persalinan memberikan pengaruh pada ibu bersalin karena dapat membantu ibu saat persalinan serta dapat memberikan perhatian, rasa aman, nyaman, semangat, menentramkan hati ibu, mengurangi ketegangan ibu atau status emosional menjadi lebih baik sehingga dapat mempersingkat proses persalinan.

Selama ini, peran pendamping persalinan tidak terlalu dipedulikan baik oleh tenaga kesehatan maupun keluarga. Bahkan di beberapa Rumah Sakit tidak memperbolehkan adanya pendamping persalinan saat proses persalinan berlangsung, jadi ibu bersalin hanya didampingi bidan atau tenaga kesehatan saja. Hal itu sangat mempengaruhi kenyamanan dari ibu bersalin itu sendiri yang pada akhirnya akan mengurangi rasa sakit dalam persalinan (Defiyani, 2013).

Intensitas Nyeri Persalinan Sebelum dan Sesudah Intervensi

Pengaruh intervensi sebelum dan sesudah teknik relaksasi nafas dalam dan pijat pada punggung menunjukkan hubungan yang bermakna terhadap penurunan nyeri pada ibu bersalin yang ditunjukan dengan $p$ value sebesar 0.002 . Hasil penelitian ini sesuai penelitian yang dilakukan oleh Ghofur (2010) dengan hasil bahwa teknik relaksasi nafas dalam efektif untuk mengurangi nyeri selama proses persalinan berlangsung karena memberikan perasaan rileks dalam mengontrol pernafasan sehingga dapat mengurangi rasa sakit.

Hasil ini juga didukung oleh penelitian Fatmawati (2011) dengan hasil bahwa intensitas nyeri sebelum diberikan teknik relaksasi rata-rata mengalami nyeri berat dan sesudah diberikan teknik relaksasi pernafasan, rata-rata mengalami intensitas nyeri ringan. Adaptasi pola pernafasan dapat mengurangi ketegangan dan kelelahan yang mengintensifkan nyeri yang ibu rasakan selama persalinan. Juga memungkinkan ketersediaan oksigen dalam jumlah maksimal untuk rahim, yang juga mengurangi nyeri, karena otot kerja (yang membuat rahim berkontraksi) menjadi sakit jika kekurangan oksigen. Selain itu, kondisi mental yang terjadi saat ibu secara sadar merileksasikan otot membantu mengalihkan perhatian ibu dari rasa sakit waktu kontraksi dan karena itu, akan mengurangi kesadaran ibu akan rasa sakit (Simpkin, Whalley \& Keppler, 2008).

Selain teknik relaksasi nafas dalam pada kelompok I juga diberikan metode pijat punggung dimana ditemukan perbedaan intensitas nyeri sebelum dan setelah intervensi, hasil penelitian ini sesuai dengan penelitian yang dilakukan oleh Janssen (2012) yang menyebutkan bahwa masase terapi yang dilakukan pada kala I fase aktif pada ibu bersalin normal primipara menunjukkan bahwa dengan melakukan masase selama 5 jam dapat menunda penggunaan analgesik epidural. Selain itu menurut Janssen (2012) pijat (massage) yang dilakukan pada punggung selama 30 menit pada ibu bersalin dapat meningkatkan kadar endorfin. Pijat menganggu transmisi nyeri dengan cara meningkatkan sirkulasi nerotransmitter yang dihasilkan secara alami oleh tubuh pada sinap neuron di jaringan sistem saraf pusat. Endorfin berikatan dengan membran prasinaptik menghambat transmisi nyeri sehingga nyeri menjadi berkurang. Pada penelitian ini intervensi pijat yang dilakukan sama yaitu dengan cara menggosok lembut dengan kedua telapak tangan dan jari pada punggung ibu bersalin setinggi servikal 7 ke arah luar menuju sisi tulang rusuk selama 30 menit.

Hasil penelitian Hosseini (2013) yang dilakukan di Iran menyebutkan bahwa pijat (massage) pada kala I fase aktif dapat mempercepat kemajuan persalinan, mengurangi lama persalinan dan penurunan kadar plasma kortisol. Disamping itu massage dapat meningkatkan sekresi opioid endogen (endorfin). Dengan massage dapat merangsang serabut syaraf berdiameter besar dan serat parasimpatis di mesencephalon yang dapat mengurangi nyeri 
dan stres pada saat persalinan dan dapat mempercepat proses persalinan.

Pada kelompok II diberikan intervensi kompres hangat dan kompres dingin. Hasil analisis juga menunjukkan hubungan yang bermakna dimana sebelum intervensi rata-rata nyeri pada ibu bersalin berada pada skala 6,97 namun setelah diberikan intervensi skala nyeri terjadi penurunan menjadi 6,60 hal ini di tunjukkan dengan p-value sebesar 0,000. Hasil penelitian ini sesuai dengan teori yaitu pengaruh stimulasi kulit dengan teknik kompres hangat dan kompres dingin terhadap penurunan persepsi nyeri kala 1 fase aktif persalinan fisiologis. Kompres menggunakan air hangat akan meningkatkan aliran darah, dan meredakan nyeri dengan menyingkirkan produk-produk inflamasi, seperti bradikinin, histamin, dan prostaglandin yang menimbulkan nyeri lokal. Panas akan merangsang serat saraf yang menutup gerbang sehingga transmisi impuls nyeri ke medula spinalis dan ke otak dihambat (Potter \& Perry, 2005).

Pemanasan merupakan metode sederhana yang digunakan pada ibu untuk meredakan rasa sakit. Stimulasi kulit melalui pemberian kompres ini dapat memberikan efek penurunan nyeri yang efektif (Tansuri, 2007). Sebagian besar ibu inpartu mengalami rasa nyaman setelah diberikan kompres hangat. Kompres panas yang diberikan pada punggung bagian bawah ibu, diarea tempat kepala janin menekan tulang punggung, panas akan meningkatkan sirkulasi ke area tersebut sehingga memperbaiki anoksia jaringan yang disebabkan oleh tekanan.

Selain tindakan kompres hangat, responden pada kelompok II ini juga diberikan intervensi kompres dingin. Kompres dingin memberikan anestesi lokal untuk mengurangi nyeri lokal dan dingin juga menimbulkan efek analgetik dengan memperlambat kecepatan hantaran saraf sehingga impuls nyeri yang mencapai otak lebih sedikit. Mekanisme lain yang mungkin bekerja adalah bahwa persepsi dingin menjadi dominan dan mengurangi persepsi nyeri (Price, 2005). Hasil ini juga sesuai dengan penelitian Mutia (2015) yang menjelaskan ada pengaruh kompres dingin terhadap penurunan intensiitas nyeri pada ibu bersalin kala I.

\section{Intensitas Nyeri Persalinan antara Kelompok yang Diberikan Teknik Relaksasi Nafas Dalam dan Pijat pada Punggung dengan Kelompok yang Diberikan Kompres Hangat dan Kompres Dingin}

Pada Penelitiaan ini membandingkan intervensi pada kelompok I dan kelompok II. Pada kelompok I didapatkan rerata sesudah pemberian teknik relaksasi nafas dalam dan pijat pada punggung sebesar $5,47 \pm 1,525$ sedangkan pada kelompok II didapatkan rerata setelah diberikan intervensi kompres hangat dan kompres

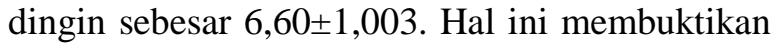
teknik relaksasi nafas dalam dan pijat pada punggung lebih efektif dibandingkan kompres panas dan kompres dingin karena rerata penurunan nyeri lebih tinggi pada kelompok I dibandingkan kelompok II dengan $p$ value $=0,001$.

Secara fisiologis teknik relaksasi nafas dalam dan pijat pada punggung dapat menurunkan nyeri, hal ini sesuai dengan teori Gate Control yang menyatakan rangsangan nyeri dapat diatur atau bahkan dihalangi oleh pintu mekanisme sepanjang system pusat neurons. Gate dapat ditemukan didalam sel-sel gelatinosa dengan tanduk tulang belakang pada ujung syaraf tulang belakang, thalamus dan system limbic (Potter \& Perry, 2005).

Berdasarkan teori dan hasil penelitian yang ada, dapat maka peneliti menyimpulkan bahwa terdapat pengaruh pemberian teknik relaksasi nafas dalam, pijat punggung, kompres hangat dan kompres dingin terhadap penurunan derajat nyeri kala I fase aktif persalinan. Dari semua intervensi yang diberikan kepada responden metode relaksasi nafas dalam dan pijat pada punggung lebih efektif dibandingkan kompres hangat dan kompres dingin dalam menurunkan intensitas nyeri pada ibu bersalin.

Pada hasil penelitian ini peneliti beropini bahwa metode pada kelompok I memadukan dua teknik yang berbeda yaitu relaksasi nafas dalam yang dilakukan langsung oleh responden dan pijat pada punggung yang dilakukan oleh bidan. Dua teknik ini memberikan rasa nyaman yang lebih baik dibandingkan dengan teknik yang diberikan pada kelompok II yaitu kompres panas dan kompres dingin yang dilakukan oleh bidan. Tindakan pada kelompok II ini relatif sama perbedaannya hanya pada air panas dan air dingin yang digunakan sehingga responden merasa lebih nyaman dengan intervensi kelompok pertama. 


\section{Pengaruh Karakteristik Responden Terhadap Nyeri Persalinan}

Hasil pada penelitian ini karakteristik responden didapatkan bahwa tidak terdapat perbedaan tingkat nyeri persalinan kala I fase aktif berdasarkan umur, paritas dan pendamping persalinan. Hal ini dapat dilihat dari nilai $p>0,05$

Hasil ini tidak sesuai dengan penelitian Magfuroh (2012) yang menemukan umur ibu yang kurang dari 20 tahun lebih merasakan nyeri hebat dibandingkan ibu yang memiliki umur 2535 tahun. Ibu yang memiliki umur resiko tinggi merasakan nyeri 4 kali lebih hebat dibandingkan yang tidak memiliki umur beresiko.

Menurut Notoatmodjo (2003) bahwa umur merupakan salah satu sifat karakteristik yang utama. Umur mempunyai hubungan pengalaman terhadap suatu masalah kesehatan atau penyakit dan pengambilan keputusan. Karakteristik pada ibu hamil berdasarkan umur sangat berpengaruh terhadap nyeri persalinan yang dirasakan, dimana semakin muda umur ibu hamil karena ketidaksiapan ibu dalam menerima sebuah kehamilan, maka akan berisiko terjadi gangguan selama kehamilan misalnya umur yang masih muda sistem reproduksi yang belum matang.

Pada faktor paritas, Intensitas nyeri 3,9 lebih hebat pada paritas ibu primipara dibandingkan dengan ibu multipara. Pengalaman melahirkan sebelumnya juga dapat mempengaruhi respon ibu terhadap nyeri. Ibu primigravida belum mempunyai pengalaman melahirkan dibandingkan ibu multigravida. Ibu yang pertama kali melahirkan akan merasa stres atau takut dalam menghadapi persalinan. Stres atau rasa takut ternyata secara fisiologis dapat menyebabkan kontraksi uterus menjadi terasa semakin nyeri dan sakit dirasakan. Ibu dalam kondisi inpartu tersebut mengalami stress maka tubuh merangsang tubuh mengeluarkan hormon stressor yaitu hormon Katekolamin dan hormon Adrenalin. Katekolamin ini akan dilepaskan dalam konsentrasi tinggi saat persalinan jika ibu tidak bisa menghilangkan rasa takutnya sebelum melahirkan. Akibatnya tubuh tersebut maka uterus menjadi semakin tegang sehingga aliran darah dan oksigen ke dalam otot otot uterus berkurang karena arteri mengecil dan menyempit akibatnya adalah rasa nyeri yang tak terelakkan (Bobak, 2005).

Pada Ibu multigravida sudah pernah melahirkan sehingga mempunyai pengalaman nyeri saat melahirkan. Ibu yang sudah mempunyai pengalaman melahirkan akan mampu merespon rasa nyeri tersebut. Ibu yang melahirkan dalam keadaan rileks, semua lapisan otot dalam rahim akan bekerja sama secara harmonis sehingga persalinan akan berjalan lancar, mudah dan nyaman (Bobak, 2005).

Hasil pada penelitian ini juga tidak sesuai dengan hasil penelitian Adam dan Umboh (2015) yaitu ada hubungan yang bermakna antara pendamping persalinan suami dengan intensitas nyeri persalinan kala I, hal ini dikarenakan adanya pengaruh secara psikologis dimana ibu yang mendapatkan pendampingan persalinan oleh suami akan merasakan adanya dukungan emosional sehingga dapat mengalihkan perhatian ibu dan menurunkan tingkat stressor. Selain itu penelitian Andarmoyo dan Suharti (2013) bahwa individu yang mengalami nyeri seringkali membutuhkan dukungan, bantuan, perlindungan dari anggota keluarga. Kehadiran orang terdekat akan meminimalkan kecemasan dan stress psikologis yang pada akhirnya akan mengurangi stimulus nyeri dan ketakutan.

Berdasarkan data-data di atas karakteristik responden yang berupa faktor umur, paritas dan pendamping persalinan tidak berhubungan karena telah dilakukan uji homogenitas sehingga tindakan teknik relaksasi nafas dalam, pijat pada punggung, kompres hangat dan kompres dingin yang menyebabkan penurunan intensitas nyeri persalinan pada ibu bersalin bukan karena faktor lain.

\section{SIMPULAN}

Terdapat pengaruh pemberian teknik relaksasi nafas dalam, pijat punggung, kompres hangat dan kompres dingin terhadap penurunan derajat nyeri kala I persalinan. Metode relaksasi nafas dalam dan pijat pada punggung lebih efektif dibandingkan kompres hangat dan kompres dingin dalam menurunkan intensitas nyeri pada ibu bersalin. Tidak ada pengaruh usia, paritas dan pendamping persalinan terhadap tingkat nyeri ibu bersalin kala I Persalinan

\section{SARAN}

Tenaga kesehatan diharapkan dapat menguasai metode teknik relaksasi nafas dalam dan pijat pada punggung agar dapat membantu meredakan nyeri persalinan kala I. Bidan juga dapat melibatkan suami/keluarga dengan menggunakan leaflet/pedoman baku metode teknik relaksasi nafas dalam dan pijat pada punggung sebagai bahan acuan. 


\section{DAFTAR PUSTAKA}

Adam, J \& Umboh, J. 2015. Hubungan Antara Umur, Paritas dan pendamping Persalinan dengan Intensitas Nyeri Persalinan Kala I Fase Aktif Deselerasi Di Ruang bersalin RSUD Prof. Dr. H. Aloei Saboe Kota Gorontalo. Jurnal JIKMU, Vol. 5 No. 2a April 2015.

Bobak. 2005. Buku Ajar Keperawatan Maternitas, Jakarta: EGC.

Cunningham. F. G. 2013. Obstetri Wiliams, Volume 1, Jakarta: EGC.

Defiany. 2013. Pendamping Persalinan Sebagai Pengurang Rasa Nyeri Saat Bersalin di RS Margono Soekardjo Purwokerto. Jurnal Ilmiah Kebidanan, Vol. 4 No. 1 Edisi Desember 2013, hlm. 190-198.

Fatmawati Lis. 2011. Pengaruh Teknik Relaksasi Pernafasan Terhadap Tingkat Rasa Nyeri pada Ibu Bersalinn Kala I di BPS Mu'rofah. Universitas Muhammadiyah, Surabaya.

Ghofur, A. 2010. Pengaruh Teknik Relaksasi Nafas Dalam Pada Pasien Inpartu Kala I Fase Laten Di Rumah Bersalin Depok Jaya. Universitas Pembangunan Nasional Veteran, Jakarta.

Hosseini. E, Asadi. N \& Zareel .F. 2013. Effect of Massage Therapy on Labor Progress and Plasma Levels of Cortisol in the Active Stage of First Labor. Science And Research Brach Islamic Azad University, Iran.

Hutahaean. 2009. Asuhan Keperawatan Dalam Maternitas dan Ginekologi. Jakarta: Salemba Medika.

Jaringan Nasional Pelatihan Klinik-Kesehatan Reproduksi (JNPK-KR). 2008. Buku Acuan Asuhan Persalinan Normal; Asuhan Esensial, Pencegahan dan Penanggulangan Segera Komplikasi Persalinan dan Bayi Baru Lahir. Depkes RI, Jakarta.
Janssen. P, Shroff. F, \& Jaspar. P. 2012. Massage Therapy and Labour Outcome : a Randomized Controlled Trial, International Journal of Therapeutic Massage and Body Work 5(4) : 15-20.

Mander, R. 2003. Nyeri Persalinan. Jakarta: EGC.

Magfuroh, A. 2012. Faktor-faktor yang Berhubungan dengan Nyeri Persalinan Kala I Fase Aktif di Ruang Bersalin Rumah Sakit Umum Kabupaten Tangerang Tahun 2012. Skripsi. Fakultas Kedokteran dan Ilmu Kesehatan. UIN Syarif Hidayatullah Jakarta.

Mutia, F, Masrul \& Detty, I. 2015. Pengaruh Kompres Panas Dan Dingin Terhadap Penurunan Nyeri Kala I Fase Aktif Persalinan Fisiologis Ibu Primipara. Jurnal Fakultas Kedokteran Universitas Andalas, Padang.

Notoatmojo Soekidjo. 2003. Pendidikan dan Perilaku Kesehatan. Jakarta: Rineka Cipta.

Prasetyo, S. N. 2010. Konsep dan Proses Keperawatan Nyeri. Yogyakarta: Graha Ilmu.

Prince, S \& Wilson, T. 2005. Patofisiologis: Konsep Klinis Proses-Proses Penyakit. Edisi 6 Jakarta: EGC.

Potter, A \& Perry. 2005. Buku Ajar Fundamental Keperawatan. Jakarta: EGC.

Reeder, Marfin, \& Griffin. K. 1997. Maternity Nursing, Eightteenth Edition, Lippincot, New York, Philadelphia.

Tansuri, A. 2007. Konsep dan Penatalaksanaan Nyeri. Jakarta: EGC.

Wall dan Mellzack. 2013.. Textbook of Pain, 6th Edition. Philadelphia: Sauders

Yuliastanti. 2013. Pendampingan Suami Dan Skala Nyeri Pada Persalinan Kala 1 Fase Aktif, Jurnal Ilmiah Kebidanan, Vol. 4 No. 1 Edisi Juni 2013. Hal.1-14. 